\title{
POR CAUSA DA REDONDILHA...: AGÊNCIA E AUTORIA EM UM GÊNERO POÉTICO*
}

\section{BECAUSE OF HEPTASYLLABIC VERSE...: AGENCY AND AUTHORSHIP IN A POETIC GENRE}

\section{Ana Elvira Luciano Gebara}

\section{RESUMO}

A escrita de poemas sempre teve um lugar na escola, principalmente com alunos e professores selecionados em concursos e festividades. Dessa forma, criou-se a representação de poema como excepcionalidade carregada de certa emoção. Nesse "contrato", ao trazer textos de variadas épocas e subgêneros, encontrava-se resistência, porque o enunciado apresentado aos alunos não se assemelhava às imagens já estabelecidas (MICHELETTI, 2000). Estudos recentes, no entanto, apontam a leitura e produção de poemas em novas chaves (NOGUEIRA, 2008; COSSOM, 2006), o que nos levou, neste artigo, à análise dessas propostas de mudança de lugar discursivo para o aluno e para o professor no momento da produção e circulação dos poemas rompendo com o modo de representação tradicional. Ao propor a elaboração de um poema, cujo tema era "a infância em redondilhas", estabeleceu-se como objetivo a agência (BAZERMAN, 2006) em todas as etapas da escrita, posicionando o professor como um editor-orientador do poeta-aluno. A aplicação foi feita durante o primeiro e segundo semestres de 2008, 2009 e 2010 no $5^{\circ}$ período de Língua Portuguesa - Estilística, em Letras - Tradutor e Intérprete. As estratégias adotadas foram as da sequência didática (SCHNEWULY, DOLZ, 2004). As interações aconteceram em sala de aula e, posteriormente, de acordo com o ritmo e necessidade de cada um, por e-mail para facilitar o registro das diversas etapas e o desenvolvimento de uma reflexão sobre o fazer autoral, as dificuldades e as soluções na busca da "obra prima" (JOLIBERT, 1994). $\mathrm{O}$ que se configurou, em cada um dos grupos, foram diferentes soluções, que ratificam a emergência de estratégias para cada atividade de escrita, promovendo, para o professor, novos lugares. Busca-se assim, na análise dessa aplicação, compreender como esses novos papéis contribuem para o aprendizado autoral dentro da concepção de poema como gênero poético (BARBOSA, 2001, PADILHA, 2011).

Palavras-chave: poema; agência; autoria.

\section{ABSTRACT}

The writing of poems has always had a place in school, mainly with students and teachers selected for competitions and festivities. In this context, the poem is a representation of specialness carried of emotions, and any other kind of poem, of varied periods and subgenres, would be reject, because the conception of the students differs from the one present in the text in front of them (MICHELETTI, 2000). Recent studies, however, indicate new possibilities for reading and production of poems at school (NOGUEIRA,

\footnotetext{
*Universidade Cruzeiro do Sul, São Paulo, São Paulo, Brasil. aegebara@gmail.com
} 
2008; COSSOM, 2006), which led us, in this article, to the analysis of these changes, new and different discursive positions, for the student and the teacher in the process of production and circulation of poems. In proposing the elaboration of a poem, whose theme was "childhood in redondilhas," it was stablished as an objective, the concept of "agency" (BAZERMAN, 2006) at all stages of writing, positioning the teacher as an editor-advisor for a poet-student. The activities were applied during the first and second semesters of 2008, 2009 and 2010 in the fifth period of Stylistics, in Translator and Interpreter Undergraduation Course. The strategies adopted were those of Didactic Sequence (SCHNEWULY, DOLZ, 2004). The interactions took place in the classroom and, subsequently, in accordance with the timing and needs of the student, by email, that also facilitated the registration of the various stages and the development of a reflection on the production, the difficulties and the solutions in the pursuit of "masterpiece" (JOLIBERT, 1994). Each group obtained different solutions that confirm the emergence of strategies for each activity of writing, promoting, to the professor, new places. The analysis of these activities is a way of understanding how these roles contribute to the learning of the authorship within the conception of poem as poetic genre (BARBOSA, 2001, PADILHA, 2011).

Keywords: poem; agency; authorship.

\section{UM HOMEM SEM PROFISSÃO'}

Já que estava à-toa resolvi fazer um poema Agora faço pra ficar à-toa

Muitas vezes, quando o aluno lê um poema como o de Cacaso, sua reação é "Mas isso é poema?" As razões para a refutação de textos poéticos de certas concepções estéticas ou de épocas mais próximas do leitor estão no tipo de ação permitida ou atribuída ao enunciado poético, que se desenvolveu ao longo de séculos e tem sido ensinada direta ou indiretamente nas escolas - um ensino que também ignora que o dito 'poema' mudou: "Já não vejo as coisas / como são: vejoas como eles querem / que as veja." (PAES, 2008). O leitor tem uma representação do gênero que envolve, em virtude de uma longa tradição, certos elementos identificados à forma composicional (majoritariamente à rima). Os elementos que compõem essa estrutura parecem se constituir como chave para a leitura de todos os poemas, mesmo que não se encaixem no objeto a sua frente, razão pela qual muitas vezes o leitor não o enxerga.

Quais seriam os gêneros poéticos relacionados ao poema para os alunos hoje? O soneto, o rondó, o vilancete, os madrigais, as canções, os epigramas, o carmen figurata, o cordel, as quadras populares, as trovas, o haicai, a tanka, a ode, o auto? Seriam só esses? E o poema de versos livres? A produção cultural do discurso poético se desdobra em muitos gêneros que devem ser estudados quanto às suas

1 do livro Na corda bamba (BRITO, 2002, p. 57). 
esferas sociais de circulação, ao estilo do gênero, à estrutura composicional, ao estilo do enunciado, ao tratamento dado ao tema, às relações com outros enunciados, ao diálogo entre as vozes presentes no enunciado.

No ensino de língua materna, nos agrupamentos ou propostas de agrupamentos para o ensino dos gêneros, uma das sugestões em relação ao poema era colocá-lo na esfera literária de forma singular - era o único gênero poético, ao passo que, na esfera privada ${ }^{2}$, havia vários gêneros com características de circulação e estrutura composicional semelhantes ao poema: quadrinha, parlenda, trava-língua e adivinha $^{3}$ (BARBOSA, 2001, cap. 3).

\section{QUADRO 1}

\begin{tabular}{|c|c|}
\hline ESFERAS SOCIAIS DE CIRCULAÇÃO & $\begin{array}{l}\text { EXEMPLOS DE GENEROS ORAIS } \\
\text { ESCRITOS }\end{array}$ \\
\hline ESFERAS PRIVADAS & $\begin{array}{ll}\text { - } & \text { quadrinha } \\
\text { - } & \text { parlenda } \\
\text { - } & \text { adivinha } \\
\text { - } & \text { trava-língua } \\
\text { - } & \text { piada } \\
\text { - } & \text { receita } \\
\text { - } & \text { diálogos } \\
\text { - } & \text { relatos de experiências vividas }\end{array}$ \\
\hline LITERÁRIA & $\begin{array}{ll}\text { - } & \text { poemas } \\
\text { - } & \text { conto popular } \\
\text { - } & \text { conto maravilhoso } \\
\text { - } & \text { conto de fadas } \\
\text { - } & \text { lenda } \\
\text { - } & \text { fábula } \\
\text { - } & \text { narrativa de aventura } \\
\text { - } & \text { narrativa de ficção científica } \\
\text { - } & \text { narrativa de enigma } \\
\text { - } & \text { romance noir } \\
\text { - } & \text { crônica literária }\end{array}$ \\
\hline
\end{tabular}

(....) (BARBOSA, 2001, p. 48) (grifos nossos)

No Quadro 1, excerto da tese de Barbosa (2001), a autora indica que essa divisão é uma recategorização dos agrupamentos ${ }^{4}$ por esferas $^{5}$, e que ainda se

2 Segundo Barbosa, gêneros da esfera privada são "gêneros primários que circulam em esfera cotidiana, familiar e foram apropriados pela escola. Como nosso enfoque principal são as esferas públicas, adotamos a solução de reuni-los num único agrupamento. Mas certamente, propostas de reagrupamentos desses gêneros seriam bem produtivas e esclarecedoras." (2001, p. 48, rodapé 33) 3 esse último pela tradição de sua gênese pertenceria ao gênero poético - cf. JOLLES, 1976.

4 Entendemos agrupamento como apresentado por Schneuwly; Dolz (2004). 
trata de um primeiro passo a ser colocado em discussão, acrescentando que seria necessário adicionar o critério "finalidade ou objetivo do enunciador/autor, tendo em vista a posição que ocupa na esfera em questão". Como se observa, a separação apresentada em relação aos gêneros literários e da esfera privada não é muito diferente de outras com preocupação teórica semelhante. Por essas semelhanças, é possível identificar que existiam alguns desequilíbrios significativos, provavelmente resultantes da impossibilidade de se fundar uma operacionalização imediata a partir da maneira como o gênero poema, por exemplo, é inserido na esfera, tendo então que se recorrer à tradição das classificações circundantes, como as da tradição da teoria literária.

Inserir alguns gêneros nas esferas privadas e um único elemento na esfera literária sob a denominação "poema" acentua a complexidade da determinação principalmente a partir de enunciados que rompem com o "isolamento" apresentando relações desses gêneros entre as esferas. Há, assim, dois percursos resultantes: fixar essa divisão (ou algo bastante similar) como uma posição na esfera literária, pela adoção de classificações mais tradicionais (que circulam pela escola - o uso das formas composicionais) ou estabelecer novas nomenclaturas (e consequentemente suas concepções) para os gêneros que circulam hoje em dia. Ambos se inserem em modos de produção de conhecimento validados socialmente, mas pertencentes a perspectivas cujo ponto de partida não está no mesmo plano. Bazerman indica o porquê:

\begin{abstract}
Nos estudos literários, a visão moderna de gêneros evoca uma tradição antiga de avaliar os trabalhos de acordo com as suas espécies, tradição que remonta a Aristóteles, mas que nos séculos XVII e XVIII se tornou moribunda dentro de uma versão normativa de decoro artístico. A rejeição romântica dessa tradição, em nome de uma expressão individual, da originalidade e da unidade orgânica, bem como o caos aí dentro instalado aumentaram o estigma desses trabalhos denominados genéricos. Mesmo entre os críticos literários que superaram tais estigmas, os estudos literários continuam se preocupando, conforme a tradição, com um número limitado de gêneros literários que já estão encaixados dentro das práticas e dos pressupostos do sistema literário, de sorte que o pensar sobre gênero é mais adaptado para o poema lírico do que para as histórias em quadrinhos; mais para essas últimas do que para um relatório sobre impacto ambiental. (BAZERMAN, 2006, p. 25)
\end{abstract}

Nesse sentido, Padilha (2011) apresenta uma nova distribuição aos agrupamentos acrescentando o de gêneros poéticos, tomando como base a circulação desses gêneros nos materiais didáticos ${ }^{6}$. Esse classificador é um elemento relevante

5 No quadro, há 9 esferas: Privadas; Literatura; Ciências; Escola; Imprensa; Publicidade; Política; Jurídica; e Produção e consumo (BARBOSA, 2001, quadro às páginas 48 e 49).

6 Padilha afirma em rodapé: "O ponto de partida para esta reflexão é a esfera de circulação observada para este grupo de gêneros: os materiais didáticos que os utilizam, procedendo a diferentes formas de escolarização." (2011, s/p) 
para quem quer trabalhar com o poema em sala de aula, pois os gêneros poéticos circulam nessa esfera, e é esperado que essa circulação ocorra. A pesquisadora parte das concepções de Bakhtin sobre poema (gêneros unilíngues e monoestilísticos) e segue:

Por fim, compreendemos que a expressão gêneros poéticos não se refere somente aos poemas, na compreensão tradicional, mas estende-se à canção (isto é, letra de canção), ao cordel e aos gêneros da tradição oral, como as quadrinhas, os travalínguas, as parlendas, as adivinhas e as cantigas de roda.

Essa escolha não foi aleatória: em primeiro lugar, ainda instintivamente, observamos que tais gêneros são alinhavados por certos traços linguísticos comuns e, em segundo lugar, para além dos poemas em suas configurações mais tradicionais, os demais foram "raptados de suas esferas" pela escola e pelos materiais didáticos de ensino da língua materna. (2011, s/p)

Padilha promove, nessa nova divisão dos agrupamentos, o rompimento das categorias anteriormente propostas por reconhecer, ao lado dos "traços linguísticos", a questão dos manuais didáticos como espaço de transposição / transformação e de circulação. Essa escolha se intensifica e se legitima ainda mais se pensarmos que os agrupamentos têm como função a delimitação de ações comuns e espaços compartilhados para o ensino dos gêneros. Seguindo essa orientação, ela acrescenta:

Expressar em poucas páginas o que vislumbramos sobre os processos didáticos envolvendo os gêneros poéticos parece quase impossível. Se pudéssemos, muito grosso modo, representar geometricamente o grupo dos gêneros poéticos, posicionaríamos tridimensionalmente, nos três eixos, tempo-espaço-valor, uma forma geométrica em que cada face seria um dos nossos pontos genéricos: poemas, letra de canção, cordéis, parlendas, trava-línguas, adivinhas, quadrinhas, cantigas de roda. A aresta de um é também aresta de outro, comungam dos mesmos vértices, mas ao mesmo tempo, mudam de posição a todo o momento, na dinâmica própria e constante dos gêneros discursivos. (PADILHA, 2011, s/p)

Tomando esse agrupamento "gênero poético" como o do poema, é possível afirmar que nossos alunos chegam à escola com experiência significativa nas arestas que ligam por exemplo a letra de canção e outros gêneros ali dispostos em planos adjacentes ao do poema. Nessas arestas, como topologicamente nos oferece Padilha (2011), os alunos trazem experiências de outros gêneros para o poema e, não raramente, classificam-no com outros critérios das fronteiras, muitas vezes, insuficientes para o enunciado poético. Essa insuficiência, no entanto, traz algo de positivo: ela expõe a impossibilidade de capturar o poético. O desafio, neste caso, é buscar a formação de uma sensibilidade, permitir a vivência dos papéis envolvidos 
no gênero poema, indo além das formas composicionais, para poder ampliar as noções ali fundadas já que essa ampliação possibilita a mudança da representação do que seja poema em seu funcionamento.

\title{
1. O QUE É UM POEMA?
}

A representação do poema como a dos demais gêneros poéticos é construída com certa rigidez resultante das atividades dos manuais didáticos que cristalizam gêneros de natureza tão dinâmica. $O$ resultado dessas balizas é uma leitura de direção única sem as trocas que a vivência com o gênero proporciona, porque uma vez que se constrói uma representação, ela passa a guiar a ação posterior dos sujeitos, como afirma Kleiman:

\begin{abstract}
Segundo a perspectiva da teoria das representações sociais, se um indivíduo expressa uma opinião sobre um objeto ou uma situação, esta os constitui. Uma vez que se desfaz a ruptura sujeito-objeto, toda a realidade é representada, individual e coletivamente: ela é reconstruída no sistema cognitivo e integrada no sistema de valores socioculturais, históricos e ideológicos. (....) São sistemas ao mesmo tempo motivadores e justificativos da ação. (KLEIMAN, 2006, p. 79)
\end{abstract}

A mudança de representação, em sala de aula, começa por novos encontros com o poema ${ }^{7}$. Dentre alguns pontos a serem revisitados, um dos primeiros é o combate à concepção de que existe uma ideia e de que o poeta, em momento posterior, a recobre de palavras. Esse tipo de representação leva invariavelmente a um equívoco: a noção de suficiência dos recursos poéticos - figuras de linguagem de som, de construção, de palavra, de pensamento, rimas, metros etc. - para se criar e se compreender o enunciado poético. Admitir que existe um conceito e depois uma espécie de adorno ou forma que o envolve é ignorar o papel da linguagem no discurso literário, como também o papel desse discurso. Embora Drummond tenha afirmado (apud BERALDO, 1990, s.p.) sobre a questão da inspiração e da capacidade de comunicação de um poema que

o que faz com que uma pessoa desconhecida que mora no Piauí escreva para gente uma carta dizendo: 'Olha, eu li um poema seu, estava angustiada, estava desesperada; seu poema é doloroso, é angustioso, mas ele me faz bem' (...) A pessoa sentiu-se confortada porque viu que um outro ser humano já experimentou aquela situação e conseguiu transmitir em verso.

7 Para as diversas representações do poema e relação com o ensino dos gêneros poéticos, cf. AUTOR, 2010, capítulo 3 . 
O que a pessoa do Piauí sentiu, ao ler, não foi sua angústia nem a primeira angústia drummondianna (que Pessoa já alertou que pode não ser do poeta) foi a junção desses sentimentos humanos a uma transfiguração dada pelas formas arquitetônicas $^{8}$ desse dizer no gênero. A angústia do poema não existe senão nesse espaço, mas, ao recriá-la pela leitura, aceitando os movimentos propostos pela dicção poética, o leitor (a pessoa do Piauí) tem a ilusão de reconhecer sua angústia inscrita nos versos.

Uma das principais características dos gêneros poéticos é fundar seu referente como interno. Essa característica acaba por traçar relações com o referente externo que, por vezes, acontecem com total adesão - o depoimento de Drummond assim nos revela. Em outros contatos com o poema, porém, essas relações parecem não acontecer - o texto se apresenta, nesse caso, como um enigma - ou ainda, em outra situação de leitura, as relações são qualificadas como banais - para o leitor -, porque o texto adere de tal forma à realidade que é insuficiente para cumprir o papel ou a representação esperada para uma forma desse agrupamento.

Para se trabalhar com os gêneros poéticos, a primeira decisão é a escolha de um deles - na proposta analisada neste artigo "A Infância em Redondilhas", escolheu-se o poema com versos heptassílabos -, tomando como critério para escolha não somente a inserção anterior em currículos, mas também a familiaridade ou o desafio que poderia trazer para os alunos. Depois dessa escolha, foi necessário inseri-lo no plano de ensino (ou no projeto temático) para que encontrasse lugar no cronograma. Submeter esse plano de ação ao coordenador ou instância superior, obtendo o aval para implementá-lo foi o passo seguinte. Novamente, no nosso caso, por se tratar de uma disciplina de um curso superior, a prática de projetos interdisciplinares não era tão frequente, sendo conduzido um trabalho dessa natureza por semestre. Assim, após a apresentação da atividade para os colegas da área de Língua Portuguesa, partiu-se para a recolha de elementos que provenientes das conversas com os colegas pudessem produzir conhecimento a respeito dele. A tarefa, etapa que considero obrigatória para qualquer projeto baseado em sequência didática, é legitimar o "conhecimento a respeito de" nas reuniões com outros docentes e coordenadores que, muitas vezes, não possuem autoridade suficiente (nem conhecimento específico) para essa legitimação, pois nesse caso não se trata de um aval global, mas de uma certificação dentro da especificidade discursiva. $\mathrm{Na}$ proposta, essas etapas envolveram os professores de Literatura das duas línguas

8 "são as formas dos valores morais e físicos do homem estético, as formas da natureza enquanto seu ambiente, as formas do acontecimento no seu aspecto de vida particular, social, histórica, etc.; (...) são as formas da existência estética na sua singularidade. (....) A forma arquitetônica determina a escolha da forma composicional" (BAKHTIN, 2010, p. 25). 
e de Prática de Tradução. Os professores de Interpretação e de Língua Inglesa tangenciaram a questão do poema em suas aulas - tema a que retornaremos mais adiante, quando forem apresentados os resultados depois de realizada a Sequência Didática - núcleo da proposta.

$\mathrm{Na}$ etapa de troca e apresentação para além da área em que a disciplina se encontra, cruzam-se conhecimentos didático e específico. Lerner (2008), ao tratar da importância do primeiro na formação do professor, indica percursos que sistematizou, a partir do planejamento de uma sessão de oficina de capacitação e que podem ilustrar quais são as perguntas que o professor precisa fazer a si mesmo para produzir esse conhecimento que será posto em atividade em sala de aula: "Realmente, nossas notas e registros mostravam que, ao planejar cada sessão de uma oficina, nós nos fazíamos perguntas similares às que costumavam nos fazer os professores, perguntas que não podiam ser respondidas apelando simplesmente para a psicologia ou para a linguística" $(2008$, p. 105). Psicologia e linguística aqui se referem a conhecimentos específicos daquela oficina e podem ser transferidos para outros temas com os quais o professor necessita trabalhar com sua sala. A autora descreve as questões que envolviam o processo com que ela se deparou e que podem ser transpostas para a preparação do nosso projeto e de outros:

Múltiplas discussões aconteciam na equipe até que chegássemos a definir a situação didática (o problema, a proposta, a consigna) que nos parecia mais adequada para que os professores aprendessem cada um dos conteúdos que queríamos ensinar-lhes (....)

A preocupação em determinar a forma mais adequada para comunicar os conteúdos aparecia não só no momento do planejamento como também da avaliação (...). (LERNER, 2008, p. 105-6)

Essa reflexão permite uma observação quanto às dificuldades, ao se estabelecer projetos ou planos de forma individual, mesmo que às vezes essa seja a condição que se apresenta ao professor (que se nos apresentou e se nos apresenta continuamente). A etapa de legitimação da escolha do que é considerado gênero poético, do material a ser utilizado e das estratégias a serem aplicadas em sala de aula se constitui como uma saída para que os pressupostos metodológicos e a abordagem adotada possam ser discutidos e reavaliados mesmo antes de entrarem em "ação" pelo grupo fortalecendo as escolhas que fizemos.

Depois de ultrapassar essas etapas - cada uma correspondendo a um enunciado concreto em um gênero diverso preparado pelo professor (plano de aula ou projeto; material a ser utilizado em sala; formulários para registro das atividades; e outros auxiliares a essa situação, como debate) -, o gênero poético escolhido chega à sala de aula. 
Na proposta "Infância em redondilhas", o objetivo era sensibilizar os alunos do $5^{\circ}$. semestre do Curso de Letras - Tradutor e Intérprete, de uma instituição particular, quanto a ritmos e metros, figuras de som e construção, aliados a um tema como parte do conteúdo da disciplina Língua Portuguesa - Estilística, sem que para isso fosse necessário recorrer somente a uma exposição teórica e destacada do texto, ou seja, que eles percebessem as formas composicionais em tensão com as formas arquitetônicas, tal como nas propostas de Schneuwly, Sandon (2002); Schneuwly, Revaz $(2002,1994)$ e Goldstein (2009); e, como efeito colateral, formar o leitor de poesia via ensino de um gênero poético, pois assim eles teriam a oportunidade de vivenciar todas as etapas: desde a entrada em um gênero até a circulação do produto final. Dessa forma, passou-se para a elaboração da Sequência Didática.

Antes de prosseguirmos na apresentação da SD, o motivo da escolha das redondilhas merece um esclarecimento que reforça a importância da representação dos gêneros poéticos para os alunos em questão. A observação começou quando os alunos estavam no $3^{\circ}$. Semestre. Em uma atividade inicial e nas seguintes relacionadas aos gêneros poéticos na disciplina de Prática de Tradução, foi possível verificar que cerca de $90 \%$ dos alunos produziam, em língua portuguesa, poemas em versos de sete sílabas métricas, a redondilha maior, independente da métrica dos textos-fonte, poemas em língua inglesa (muitos deles em versos livres). Com a professora dessa disciplina, foi possível acompanhar esse exercício e alguns posteriores que apontaram essa particularidade. Como a redondilha parecia estar associada a uma concepção do que fosse o verso em língua portuguesa para esse grupo, houve a decisão de utilizá-lo de modo a desenvolver suas potencialidades, uma vez que, embora a métrica fosse o verso heptassílabo, o esquema rítmico de cada verso era variado em virtude da falta de consciência sobre esse nível do poema.

\section{A SEQUÊNCIA DIDÁTICA E O POEMA}

Para nós docentes, há a necessidade de conhecer os gêneros acadêmicos, os didáticos e, simultaneamente, aqueles com os quais trabalharemos e que provêm de diversas esferas de circulação social além dos muros da escola. Essa gama de gêneros aliada aos espaços de intersecção entre eles na ação do professor exige uma proficiência para a qual nem sempre estamos preparados e que pode interferir na transposição didática, ou seja, na introdução do gênero e no trabalho referente ao ensino da leitura e produção desse gênero. É importante que se tenha consciência de que a ação docente exigirá o domínio de vários gêneros provenientes de diferentes 
esferas, retirando assim o peso total de suas ações somente no conhecimento específico sobre o gênero com o qual vai trabalhar em sala de aula (embora esse seja basilar). Como afirma Matêncio sobre as concepções de língua(gem) que podem ser transferidas para conhecimentos específicos de outra esfera:

E se hoje se fala com tranquilidade da variabilidade da língua e dos gêneros textuais, da multiplicidade de discursos, não se pode esquecer de que não há ainda uma reflexão sistemática e consistente acerca de como transformar os objetos de estudo produzidos no campo dos estudos da linguagem em objetos de ensino. (MATÊNCIO, 2006, p. 96)

Um dos gêneros que possibilitam a transposição didática é a Sequência Didática (SD). Por organizar o conhecimento a respeito do gênero e por apresentarse como instrumento didático para o aluno, a SD, sempre inserida num projeto temático ou mais especificamente, um projeto de ação ${ }^{9}$ permite que o professor, ao produzi-la ou adaptá-la para a sala de aula ${ }^{10}$, escolha como trabalhar com cada um dos elementos (tema, forma composicional e estilo), quanto tempo dedicará a cada um deles, como avaliará o conhecimento dos alunos em relação ao gênero estudado.

Os processos de focalização dos dados a respeito do gênero e a hierarquização dos conhecimentos sobre ele permitem que se minimize um dos pontos mais frágeis de toda transposição didática: o artificialismo decorrente do modo como se insere o gênero no espaço escolar. Se se pensar nas notícias de jornal, nas receitas de bolo, nas bulas de remédio, nos boletins de ocorrência, ou ainda nas cartas do leitor, a recuperação dos espaços de circulação diminui esse artificialismo. Os alunos podem mandar as cartas para os jornais. Podem montar um jornal na internet ou no mural da escola. Podem ir à cantina ou qualquer outro espaço culinário e preparar a receita. Podem verificar se a bula está correta ou não, consultando um especialista. Podem auxiliar alguém em situações em que o boletim de ocorrência for necessário. Em todas essas ocorrências, cada um dos gêneros precisa superar os umbrais da sala de aula para que se efetive a ação. Ocorre o mesmo com os gêneros poéticos? Qual (is) é (são) o(s) seu(s) espaço(s) de circulação? É possível ouvir o poema, nós, "almas penadas do mundo do consumo"? (PAES, 2008, p. 403).

No caso dos poéticos, esses espaços apresentam uma característica particular como afirma Maingueneau:

9 "projeto de atividades complexas orientado para um objetivo preciso de certa amplitude: organizar uma visita, uma exposição, um espetáculo, participar de uma ação de grande porte (feira de ciências, salão, de escritos), publicar uma coletânea de poemas, receber correspondentes, arrumar o pátio...." (JOLIBERT; SRAÏKI, 2008, p. 32) (grifos nossos)

10 Há algumas publicações que se encaixam nesse gênero (sequência didática) embora não existam muitos títulos. Um exemplo de vinculação explícita a essas concepções é a Coleção da editora FTD: Trabalbando com Gêneros do Discurso, cujos volumes abordam os gêneros receita, narrativas de enigma, cartas de reclamação e solicitação, contos de fadas, fábula e notícia. 
Quando se trata de criação literária, metáforas topográficas como as de "campo" ou "espaço" só têm validade entre aspas. Claro que o espaço literário faz, num certo sentido, parte da sociedade, mas a enunciação literária desestabiliza a representação que se tem normalmente de um lugar, algo dotado de um dentro e de um fora. Os "meios" literários são na verdade fronteiras. A existência social da literatura supõe ao mesmo tempo a impossibilidade de ela se fechar em si mesma e a de se confundir com a sociedade "comum", a necessidade de jogar com esse meio-termo em seu âmbito. (....) Enquanto discurso constituinte, a instituição literária não pode de fato pertencer plenamente ao espaço social mantendo-se antes na fronteira entre a inscrição em seus funcionamentos tópicos e o abandono a forças que excedem por natureza toda economia humana. Isso obriga os processos criadores a alimentar-se de lugares, grupos, comportamentos que são tomados num pertencimento impossível. (MAINGUENEAU, 2006, 91-92)

As ações que cercam e representam o projeto sistematizado em sequências didáticas, nesse quadro de "paratopia" (MAINGUENEAU, 2006), se apresentam como instrumentalização produtiva ao professor, pois, nas atividades desenvolvidas, é possível discutir as fronteiras apontadas, sem que com isso o gênero se artificialize, uma vez que ele é formado por fronteiras em cuja margem pode se situar o espaço escolar, como apresenta Padilha (2011). A SD, nesse percurso, possibilita a junção de atividades por meio dos gêneros, como os saraus; os cantos de leitura, os espaços para dizer e apresentar poemas; a exposição em murais. Todas essas ações, situadas em sistemas de gêneros, tornam o espaço escolar, espaço de circulação do gênero poético mesmo que durante um período determinado - "Sim, mas vamos à coisa concreta: / você fala de fósforos / ou de poetas?" (PAES, 2008, p. 404). Destitui-se o "como se fosse" trazendo para a escola a legitimidade de "ser" um desses lugares. Atenua-se, também, o fato de a literatura ser "frequentemente escrita e lida em momentos de contemplação, aparentemente (mas de forma categórica) destacada das circunstâncias mais imediatas da vida, o caráter social do gênero torna-se menos visível." (BAZERMAN, 2006, p. 25)

Se o espaço da sala de aula estava legitimado dentro dessa perspectiva, o fato de a proposta de produção textual ser uma tarefa ainda se constituía como problema uma vez que os poetas e prosadores são aqueles que escrevem sem que ninguém peça (salvo raras ocasiões). Como legitimar a atividade? Seguindo a concepção de gênero de discurso, buscou-se a princípio propor essa atividade como desafio de leitura para estimular o desenvolvimento da necessidade de escrever posteriormente, refletindo uma primeira necessidade na relação professor - aluno. Durante a apresentação da atividade, os poemas de base foram "Autopsicografia" (PESSOA, 1980, p. 104) - base para a discussão de como os temas são processados no poema e no heptassílabo como o da SD -, e "Meus oito anos" (ABREU, s.d, p. 204) - base para a discussão do tema "infância". Seguindo a estrutura da aula de Literatura Brasileira (e tomando algumas das vivências que os alunos tinham nessa 
disciplina), conversamos sobre o poema, identificamos o contexto de produção e poemas afins (que eles trouxeram dessas aulas), voltamos ao poema e procuramos quais elementos formavam a imagem da infância ali constituída.

Para essa etapa foi utilizado o instrumental da Estilística em todos os seus níveis, a saber, da enunciação, da frase, da palavra e do som, tal como formula Martins (2003). Invertemos, no entanto, essa sequência, contrariando a dos livros e manuais de Estilística, por acreditarmos que a estilística da enunciação recobre o texto como um todo, situa o trabalho do sujeito enunciador, nesse caso, um sujeito lírico, para depois observarmos os elementos nos outros níveis até a vassalagem fônica, nas figuras de linguagem do som. Em ambos os poemas ("Autopsicografia" e "Meus oito anos"), foi possível observar um ethos" potente e, ao mesmo tempo, melancólico. No poema de Pessoa, a potência é a de poeta, que cria de forma tão precisa e intensa que convence a todos; já em Casemiro de Abreu, a força está nas ações contínuas e físicas do sujeito lírico que domina o espaço do seu passado levando o leitor a sentir-se extenuado com tanta atividade. Partindo da avaliação que os sujeitos líricos apresentam, um de seu trabalho e outro de sua infância, avançamos nas discussões, em seguida, a proposta foi, para cada aluno, escrever um poema em redondilhas sobre a infância (questões 1 a 4, no quadro 2).

Em seguida, apresentamos uma série de questões que foram discutidas em grupos de 5 a 7 alunos e cujos resultados foram apresentados para a turma.

As questões-guia para essa etapa foram:

\begin{tabular}{l} 
Quadro 2 \\
\hline 1. Leia o poema de Casemiro de Abreu. \\
2. Qual a imagem que o poeta apresenta da infância? \\
3. Coincide com a imagem que a estética do Romantismo apresentava sobre a infância? \\
4. Qual a imagem que você tem da infância? As imagens coincidem? Quais são as semelhanças \\
(caso existam)? Quais são as diferenças (caso existam)? \\
5. Para escrevermos um poema sobre memórias da infância, vamos começar com alguns \\
elementos dessa memória. Faça uma lista de coisas da infância de que você se lembra. Esses \\
elementos podem ser divididos por categorias: cognitivas, sensoriais, emotivas... \\
6. Vamos conversar com a classe e ver quais os elementos que todos colocaram. Nesse momento, \\
você pode fazer a escolha de quais "memórias" você colocará no poema. Lembre-se de Pessoa \\
("autopsicografia"), a emoção pode ser a alheia que você faz sua, ou a que vem do outro para \\
de novo ser sua no texto. \\
\hline Elaborado pela autora \\
\hline
\end{tabular}

11 Utilizamos na Estilística discursivo-textual, o ethos, como uma das categorias de análise da enunciação. Sobre o conceito de ethos, cf. Maingueneau, 2008. 
As categorias da questão 5 foram o motor para a constituição das imagens e sensações que os alunos teriam à disposição para escolher no momento e que fossem relevantes para elaborar as estruturas dos poemas. Alguns deram definições da infância (época da inocência; o paraíso; quando eu era feliz e não sabia...); outros apresentaram suas sensações ligadas a esse período (o gosto do sorvete de chocolate misturado à areia da praia nas férias; o gosto da comida do refeitório do internato; cheiro do bolo da casa da avó); outros ainda falaram de suas experiências com pessoas mais velhas por quem tinham afeto, amigos e brinquedos dos quais sentiam falta. Esses elementos da memória eram fragmentos, partes de mosaicos em cada uma das folhas que pouco a pouco começavam a tomar forma, e esse modo de tratar a memória poderia se tornar um procedimento artístico.

Dada a natureza do tema, os estudantes-poetas puderam escolher se teriam como tema a própria infância ou a de outro (questão 6); essa era a maneira de estabelecer o ponto de vista do enunciador, trabalhar os graus de subjetividade e o ethos. Apenas uma aluna se manifestou dizendo que sua infância tinha sido muito dura e que ela preferia tratar da infância do filho mais velho. Houve outros que preferiram tratar do tema de forma expositiva, mas acabaram por apresentar a própria infância. Nos poemas, no entanto, o elemento que os fez sair da posição de relato foi a coerção dada pela métrica e o esquema rítmico impostos pelo exercício, pois exigiam que o ritmo da prosa do relato fosse transformado à medida que os versos eram elaborados - a coerção mostrou que podia se revelar uma força subversiva.

$\mathrm{Na}$ aula seguinte, tratou-se das questões 7 a $8^{12}$, algo próximo a uma "tempestade de ideias"13. Cada um dos alunos-poetas passou a fazer sua lista ou uma espécie de mapa mental com as palavras que se entrelaçavam com as imagens e objetivos fixados na aula anterior. O efeito colateral das escolhas realizadas (mais ainda do processo para realizá-las) foi a consciência dos fatos linguísticos, de uma lida com matéria de poesia: "conciso? com siso/ prolixo? pro lixo" (PAES, 2008, p. 289). Em geral, mesmo os alunos dos Cursos de Letras têm dificuldade em utilizar os termos adequados a cada fato linguístico, preferindo, muitas vezes, palavras de uso comum para designar esses fatos. Ao procurar palavras abstratas ou concretas, substantivos ou verbos, adjetivos, preposições e outros, foi possível a princípio

12 "7. Há muitos tipos de texto que podem ser utilizados no seu poema. Há tipos de texto: narrativo, descritivo, dissertativo etc. Para cada um deles, você deve escolher palavras concretas ou abstratas; verbos no tempo presente ou pretérito passado do indicativo; etc.

8. Para escrever um poema, essas palavras devem ser escolhidas pela relação que mantém entre si. Como será seu poema? Melancólico? Alegre? Cheio da peraltice de criança? Saudoso? Para cada uma dessas avaliações do passado, você precisa decidir quais são as palavras mais adequadas."

13 Tradução livre de brain storm. 
ampliar o conhecimento aplicado desses componentes dos poemas, para então passar a um conhecimento metalinguístico utilizado na segunda fase da SD para poder discutir o poema com a professora-editora.

A partir dessa aula, cada um dos estudantes foi elaborando seu poema e discutindo o processo, trocando ideias sobre suas dificuldades em sala de aula (havia sempre horário para essa troca agendado anteriormente) ou por email. Esses encontros permitiram o desenvolvimento das atividades epilinguísticas, "aquelas que suspendem o desenvolvimento do tópico discursivo (ou do tema ou do assunto), para, no curso da interação comunicativa, tratar dos próprios recursos linguísticos que estão sendo utilizados, ou de aspectos de interação." (TRAVAGLIA, 2002, p. 34) Essa suspensão foi estimulada nos encontros, pois permitia que a consciência dos fatos linguísticos relacionados aos gêneros poéticos acontecesse, e um dos resultados foi o desenvolvimento de um saber metalinguístico, especialmente ligado ao fazer poético. Por serem conscientes, ao contrário das atividades epilinguísticas, que nem sempre o são, as atividades que envolvem a metalinguagem têm como base teorias e métodos de análise de língua. Em nosso caso, os alunos se voltavam para a teoria literária e para a estilística, com as quais tinham contato imediato no semestre, na releitura e na refacção dos poemas.

A princípio, durante os momentos de orientação, ocorriam pedidos: "você pode me ajudar com as rimas?"; "a métrica está correta?"; "posso mesclar redondilha maior e menor?" Em geral, essas solicitações refletiam a insegurança em relação à escrita dos gêneros poéticos e, de certa forma, os alunos buscavam um caminho para finalizar uma atividade "da escola". Essa parece ser uma representação comum das atividades de produção textual:

Essa escrita para o desempenho escolar deixa os alunos com a crença de que a escrita sirva principalmente para ganhar a aprovação de uma autoridade e os deixa com medo de serem corrigidos e, dessa forma, humilhados. Essa crença nega aos alunos o sentido de todas as outras coisas que podiam se realizar na escrita. (....) Ou, mais precisamente, o aluno escreve apenas para um examinador, para evitar ser corrigido e para ganhar boas notas. (BAZERMAN, 2006, p. 15)

Dessa forma, essa primeira iniciativa dos alunos não permitia que a professora saísse de seu papel de avaliadora. Para contornar essa situação, recorreu-se novamente a Bazerman, quando aborda a noção de posição retórica: "A esse tipo de escrita escolar vazia falta o que Wayne Booth chamou de uma posição retórica, que forma uma relação concreta entre um escritor engajado e uma audiência interessada em um assunto significante para ambos" (BAZERMAN, 2006, p. 15). Buscou-se, então, para o professor, outra posição, a de editor, que está entre os autores e os 
futuros leitores, e que não tem como função atribuir uma nota, mas estabelecer a possível audiência. A mudança de posição da professora promoveu nos alunos outro deslocamento: a antecipação do encontro com a audiência.

Muitos alunos trouxeram outras produções que haviam feito fora do curso para que os professores lessem. Outros alunos levaram seus poemas para suas famílias, para o local de trabalho ou colocaram nas redes sociais. Com essa atitude, encontraram a posição retórica, mencionada por Booth e Bazerman. As conversas não eram simplesmente entre o aluno-poeta e a professora-editora, mas entre todos esses outros leitores que opinavam e que ora faziam o aluno feliz e equipado para o confronto com o professor-editor ora faziam com que ele/ela ficasse buscando com o editor razões para descartar a opinião alheia. Além disso, o público externo trouxe outras dimensões centrais para os gêneros literários - sensações/emoções, experiências estéticas e críticas. Os alunos-poetas puderam experimentar essas reações e, muitas vezes, voltar ao texto e encontrar soluções a partir dessas leituras. Tomar a relação escritor - audiência como fundadora recolocou na escrita do poema os elementos contextuais, o valor das estruturas e temas, a imagem de si no discurso.

A posição retórica é um dos pilares para a agência do aluno. Para que ela se efetive, são necessários os conhecimentos sobre o gênero, seu espaço de circulação, os participantes, sua função, a estrutura composicional, uma vez que esses elementos determinam as ações que também constituem o gênero. Esse entrelaçamento, em geral, não chega a ser incorporado na escola, onde a representação da escrita de qualquer gênero implica avaliação. $E$, nesse ponto, a representação da escrita no espaço escolar alcança seu limite. Para recuperar a agência dos alunos, estendendo-a para além dos espaços da escola, uma vez que esta é responsável por seu ensino, é preciso tomar a concepção de gênero como algo que "dá forma a nossas ações e intenções. É um meio de agência e não pode ser ensinado divorciado da ação e das situações dentro das quais aquelas ações são significativas e motivadoras." (BAZERMAN, 2006, p. 10). Por isso, a ampliação da audiência dos alunos foi tão significativa na atividade proposta.

Como o docente pode reagir a essa influência externa? A aproximação do espaço externo com o da sala de aula é essencial e renova a confiança no que se refere às tarefas escolares. Fenômenos como o da fanfiction e os blogs também devem ser considerados como uma forma de se tornar significativa a escrita de gêneros literários. Nos nossos dias, é também comum observar a presença de grupos que promovem saraus para apresentação dos escritores da comunidade. São outras vozes que legitimam a produção dos alunos, que dialogam com o que é apresentado para eles como sendo o papel da escrita dos gêneros. Nos saraus, nos sites de fanfiction 
e blogs, há também avaliação e ela ocorre não somente por uma matriz (como na sala de aula e nos concursos), mas por meio de vários critérios de grupos diversos em diálogo com a tradição de cada gênero e de cada tema proposto no tema ou pelo grupo. O docente, nesse quadro, precisa abrir seus critérios e compreender o valor de cada uma dessas avaliações, explicando aos discentes o papel do cânone para a cultura e para uma época. A negação dessas experiências, no entanto, seria a negação da existência dessas relações e a possibilidade de se desenvolver o papel crítico do leitor.

Como no Curso de Letras havia um Sarau por semestre, organizado pela coordenação e pelos discentes, os alunos da turma em que se desenvolvia a atividade com o poema pediram para ter um espaço para apresentação. A sequência para a declamação dos poemas foi estabelecida pelo grupo e, para a surpresa de todos, eles compuseram coletivamente um poema para explicar o que havia acontecido no período em que desenvolveram a atividade. Os dois primeiros versos desse poema eram: "Por causa da redondilha / quase não vejo minha família". Essa postura intensa e irônica foi a forma como eles se apresentavam e justificavam a presença no palco. Era também um aviso para as turmas que viriam - uma espécie de camaradagem que se desenvolve entre escritores e poetas. $\mathrm{O}$ que se seguiu foram poemas diversos, que formavam um quadro como no pontilhismo em que cada texto poético permitia que se observasse um aspecto, uma visão da infância que seria retomada em uma imagem maior poetizada em todas as infâncias daquele grupo. $\mathrm{O}$ público respondeu favoravelmente e muitos alunos de outras turmas perguntaram se fariam o mesmo no semestre seguinte. Mais do que a satisfação docente, os alunos-declamadores consideraram essa resposta uma aprovação a sua produção.

A produção do poema foi o fator essencial à mudança de representação do gênero. A transformação ocorreu nas trocas entre os discentes e o docente: cada um dos alunos-poetas questionou a escrita do gênero poético em questão de maneiras diversas. Pode-se reuni-las em duas posturas que tinham uma mesma convicção inicial: "não conseguimos escrever poemas", seguida da pergunta-acusação: "por que você quer que façamos isso?". Essa convicção provocava duas reações que foram tão importantes para estimular os alunos quanto para criar obstáculos à atividade. O grupo mobilizado tomou a escrita do poema como um desafio, envolveu-se na escolha dos temas, nas rimas, nas palavras que cada um utilizaria. Já o grupo resistente iniciou a atividade como uma tarefa. Esses posicionamentos derivados da convicção inicial são a prova do que a teoria da representação social formula - que a opinião sobre um objeto o constitui (KLEIMAN, 2006). Por essa razão, durante os encontros, buscaram-se mudanças e fortalecimentos em ambas as convicções tanto quanto o desenvolvimento dos elementos composicionais. 
Embora a preocupação tenha sido mais intensa com o grupo "em conflito com a atividade", problematizar os posicionamentos, apontar os avanços, questionar os resultados foram as estratégias utilizadas para desenvolver a postura retórica de poeta alcançando dessa forma as bases para a escrita significativa. As primeiras dúvidas eram simples e se referiam ao esquema métrico. Quanto à representação de si, eram apresentadas afirmações em tom de desculpa, cujas variações gravitavam em torno de "não sei se ficou bom, não sou bom/boa com poemas". A responsabilidade pelo ajuste e pela avaliação da qualidade da produção era atribuída nos e-mails e nos encontros ao docente - situação que precisava ser mudada. Para cada caso, houve estratégias diversas com o intuito de deslocar a responsabilidade para os alunos, desde oferecer duas ou mais soluções; apontar elementos em desacordo com o requerido para a atividade e pedir soluções; até elaborar breves comentários ao poema que necessitavam de resposta dos alunos.

A partir do momento em que os alunos-poetas mudaram sua relação com a escrita, a busca de um texto final - sua obra-prima (JOLIBERT, 1994) - se desdobra em mais de uma tentativa. Isso não significa que os poemas tenham alcançado, em sua totalidade, os objetivos para a atividade realizada. No entanto, um deslocamento com resultados positivos em relação à escrita e, consequentemente, em relação à leitura (voltamos a isso mais adiante), tem como consequência a formação mais ampla do aluno, que pode buscar a cada atividade outras posturas retóricas: o alunocontista; o aluno-romancista; enfim, o aluno-escritor e, por fim, o escritor para alguns deles. Assim as suas posturas, "sou poeta com certeza", e "posso escrever poemas", trouxeram a ideia de que se pode pensar na escrita na escola não mais em termos absolutos, divididos em uma pirâmide em que os que podem escrever estão no topo e representam uma fração pequena. Há mais lugares a serem ocupados e nem todos precisam ser o da publicação de livros, mas que certamente envolve a circulação dos textos.

\section{OS EFEITOS COLATERAIS DE ESCREVER TEXTOS POÉTICOS}

A denominação "efeitos colaterais" pode não corresponder à realidade das atividades desenvolvidas com os alunos uma vez que a escrita e a leitura se relacionam de forma a criar determinações mútuas como vários autores já demonstraram ${ }^{14}$, mas nos pareceu relevante assim denominar, porque os estudantes trouxeram para o

14 Entre muitos dos autores já mencionados no artigo destaco Kleiman; Schneuwly e Dolz e em especial para os gêneros literários, Cossom. 
momento de avaliação da atividade o fato de se sentirem com mais proficiência na leitura de textos poéticos, e também pelo mal-estar que despertou em alguns (a expressão efeito colateral é usada muitas vezes com sentido de efeito indesejado). Por essa razão, à medida que os alunos produziam seus poemas, buscavam em poetas legitimados pelo cânone inspiração e recursos. Por vezes, os alunos "confessaram" suas influências que, como era de se esperar, foram além de Casemiro de Abreu e seus oito anos. As "fontes" de inspiração incluíam poetas de outras línguas, especialmente de Língua Inglesa, em função das disciplinas que os estudantes cursavam, aos quais eram justapostos contos, romances, filmes e fotografias. Todos esses outros textos e gêneros também possibilitavam ao professor compreender como são os sistemas envolvendo os gêneros ligados às artes e quais são os gêneros de alimentação temática desse grupo, que não serão necessariamente o de outro que venha a participar desse processo.

A leitura de textos de gêneros literários pode, muitas vezes, trazer desconforto para o professor e para os alunos. $\mathrm{O}$ docente não rejeita esses textos quando está na posição de leitor, mas, algumas vezes, prefere trabalhar em sala com os de outras esferas. No entanto, se houver necessidade de trabalhar com os literários, a preferência pelos prosaicos se manifesta. Esse é um dos casos que ilustra como essa esfera problematiza a sala de aula, pois coloca em conflito a necessidade de homogeneização da escola com a profusão de valores e estéticas que acontecem na literatura. Uma das formas de construir a agência que o docente pode exercer em sala de aula envolve uma instável construção de conhecimento e instâncias de legitimação desse conhecimento. A ação se dá nos diversos gêneros envolvidos para a disciplina pela qual o professor é responsável, desde a ementa, a publicação para a inscrição, planos de aula, programas de curso, material de apoio, os trabalhos dos alunos e as avaliações do professor. Em todos eles, a representação que o professor construiu dos gêneros poéticos é posta sob exame. Assim ele não precisa gostar de todos os gêneros com os quais trabalha, porém a proficiência de leitura e escrita é necessária. Se pudermos utilizar uma comparação, ao professor é indispensável que possa, como se observa nos esportes, saber treinar, porque, ao treinador de atletismo não se exige que seja rápido como um velocista (lembremos de Bolt), dele, exige-se, no entanto, que saiba treinar o atleta para que aproveite toda a sua potencialidade. Essas competências são desenvolvidas na elaboração do material que articula pesquisa e construção de conhecimento, e na experimentação com os textos.

Para os alunos, a dificuldade se concentra no ato de ler reflexivamente, principalmente na aceitação e/ou compreensão das interpretações autorizadas 
pelo professor no espaço da sala de aula. Algumas vezes, os discentes apresentam interpretações particulares testando os limites da autoridade do professor para legitimação de leitura. Uma mostra desse tipo de tensão na sala de aula está na tese de Cynthia Agra de Brito Neves (2014) ${ }^{15}$. A pesquisadora acompanhou aulas de Literatura no Ensino Médio na França e no Brasil analisando as estratégias e metodologias utilizadas, as representações presentes, e os resultados desses trabalhos. Em seu relato das aulas observadas, é possível encontrar alunos que apresentam interpretações "peculiares", confrontando-se com o que os críticos e o professor indicam como parâmetros para a leitura do texto. Em alguns momentos, há interesse por elementos contextuais e biográficos para explicar de maneira peremptória a construção do texto. Ambas as posturas mostram como os alunos resistem a construções de leitura que consideram externas a eles. Nesse aspecto, a escrita do poema permitiu que essa construção partisse dos próprios alunos e a troca entre as leituras do professor e dos estudantes ocorreu com menos conflito dada a negociação de sentidos exercida durante todo o processo.

Ao utilizar os recursos poéticos de maneira a desenvolver o tema e a imagem desejada, os alunos também puderam criar hipóteses sobre o que o poeta havia construído em seu texto. Eles não consideravam mais que o professor estava "viajando na maionese" - como muitos deles avaliavam com frequência quando interrogados sobre o processo de interpretação antes das atividades. É verdade que os conflitos não sejam dirimidos (nem é desejável que sejam), mas muitos alunos se interessaram pela atividade interpretativa e passaram a considerar a voz do outro justaposta às suas. $\mathrm{O}$ comentário dos poemas, o diálogo com a crítica, as resenhas de livros, as publicações em blogs, os livros-texto das disciplinas passam a constituir a leitura do poema tal como fizeram parte da escrita desse gênero. Esse desdobramento da atividade se efetivou em função do envolvimento de outros professores que explicitavam os imbricamentos entre ações e textos. $\mathrm{O}$ alcance dessa atividade tem como limitação - ou ampliação - as relações estabelecidas entre os vários atores envolvidos na formação do aluno.

\section{NA COMPANHIA DA REDONDILHA}

O ensino dos gêneros poéticos é sempre singular, considerando a primeira acepção do verbete no Grande Dicionário Houaiss da Língua Portuguesa Beta

\footnotetext{
15 Tese defendida no Instituto de Estudos da Linguagem / Unicamp, cujo título é "A Literatura no ensino médio: os gêneros poéticos em travessia no Brasil e na França".
} 
(2012): "único de sua espécie, distinto, ímpar" e a ela justapondo duas outras: "significativo" e no domínio da lógica, "que se aplica a um sujeito único". A cada proposta ou a cada grupo, as respostas se desenvolvem de forma diversa trazendo para a sala de aula aquilo que se experimenta nos diversos setores artísticos, com tendências, estéticas e propostas múltiplas. Assim, absorver as condições que emergem da atividade pela relação singular que constroem revela-se o papel mais difícil que o professor deve exercer: deslocar-se no sistema criado localmente buscando respostas para aquele grupo sem perder um diálogo maior com as outras instâncias constitutivas do discurso literário (MAINGUENEAU, 2006). A dinamicidade da estratégia metodológica é essencial, pois essa é a natureza do objeto.

A elaboração de atividades, que absorva essa preocupação na fase de diagnóstico de cada turma, considera não somente os insumos da produção escrita, mas também alia a essa produção os relatos dos alunos sobre seus gostos, a concepção que eles têm dos gêneros poéticos, poetas e poemas preferidos, que passam a constituir a representação desses gêneros, permitindo que se estabeleça um diálogo efetivo entre lugares reais do discurso, o do docente e o do discente. Uma das formas de se delinear as representações presentes que privilegia essa busca é trabalhar com o texto poético de temática metalinguística. Nessas produções, é comum verificar "fórmulas" tais como "poesia é...", ou "o poema é...", em que a oração declarativa que utiliza o verbo "ser" auxilia na elaboração de uma descriçãoconceito. Trata-se de um dos primeiros componentes da representação aos quais outros podem ser acrescentados pelo professor a partir da análise dos recursos enunciativos e estruturais utilizados pelos alunos nos textos produzidos. A imagem de poesia no diagnóstico é delineada em forma de peças de um mosaico, e um dos objetivos das atividades com os gêneros poéticos é desenvolver a percepção do todo, mas de um 'todo' sempre aberto a mudanças, ampliando gradativamente os conhecimentos discursivos a respeito dos gêneros da esfera literária.

O trabalho com as temáticas se configura nesse quadro de relações genéricas como um importante recurso a ser estabelecido e aprimorado nas atividades. No caso analisado neste artigo, o cruzamento da temática (infância) e o recurso composicional (redondilha maior e menor) permitiu sensibilizar os alunos para as forças presentes no gênero. Há temas que são considerados centrais para cada época ou estética da esfera literária; há outros que se repetem recondicionados pelas coerções do espaço de circulação e a comunidade em que o gênero se insere. Um dos temas frequentes, que permite a reavaliação e explicitação dos gêneros poéticos é a metalinguagem, como indicado acima, que aparece no século XX como busca 
de sentidos para o poético. Tezza afirma que há "uma desesperada falta de mitos a quem cantar, convincentemente, a nossa poesia ${ }^{16}$ : é a autoridade poética que está em crise." (TEZZA, 2003, p. 288) A crise da autoridade se coloca na constituição da voz do poeta, uma vez que "num mundo fragmentário e prosaico como o nosso, não é tarefa fácil sustentar o poder dessa linguagem sem se entregar aos lugares comuns da cultura da massa ou aos universais poético-religiosos, que, parece, são a hegemonia que nos restou. Não é fácil, mas é possível. (...)" (TEZZA, 2006, p. 215). Em sala de aula, a possibilidade anunciada por Tezza se configura em propostas de atividades que tomem como centrais esses elementos. Uma dessas propostas é a de Carvalho (2015), apresentada no capítulo "Poemas Metalinguísticos de Ferreira Gullar: uma Proposta de Sequência Didática Interdisciplinar", que tem como objeto os gêneros poéticos, estabelecendo, na atividade, a produção do poema e a elaboração de um comentário-análise do aluno como complementares para o espaço de reflexão sobre o fazer poético.

O trabalho com os gêneros poéticos é, nesta perspectiva que adotamos, interdisciplinar, se pensarmos nas disciplinas escolares de língua materna e estrangeira e suas literaturas, tangenciando a de História e de Filosofia, a depender dos níveis em que se propõe a atividade, pois as relações se complexificam à medida que nos deslocamos da Educação Infantil até o Ensino Superior. É também um trabalho entre gêneros, uma vez que os relatos dos alunos, as análises de outros textos poéticos, os livros didáticos e de crítica literária, os próprios textos poéticos, os comentários orais de colegas e demais leitores fazem parte dos insumos necessários para a leitura e produção dos gêneros em questão. É ainda um trabalho de constituição da autoria pela exigência instituída pelo gênero e que pode ser sistematizada como Fiad (2008) apresenta em seu texto "Ensino e Autoria"

- a noção de autoria deve ser pensada junto às noções de singularidade e estilo;

- a autoria é detectável através de indícios e aqui deve remeter-se às considerações de Ginzburg (1986) sobre o paradigma indiciário;

- para se dizer que um texto tem autoria, não é suficiente que ele seja um texto correto gramaticalmente, nem que seja textualmente satisfatório. Isso significa que, na sua visão, as marcas de autoria são da ordem do discurso e não da gramática ou do texto;

- duas atitudes de um autor seriam "dar voz aos outros" e "manter distância" em relação ao que dizem e em relação a seus interlocutores;

16 "nossa" entendido aqui como a poesia do século XX e início do XXI. 
- a autoria é encontrada no "como" e não no "o quê" é expresso. (FIAD, 2008, p. 218)

Assim, sentir-se parte de uma comunidade, mesmo que seja entre os muros da escola, e responder com seus textos e comentários a esse grupo na posição de leitores e pares de criação de textos poéticos fortalecem a postura retórica dos estudantes-poetas e são parte do trabalho com esses gêneros. Seja na companhia da redondilha, seja no afago do cordel, ou ainda no jogo do limerick, as atividades com poemas constroem lugares para os alunos ocuparem, que são feitos e refeitos a cada leitura ou produção dentro, e, segundo nossa expectativa mais ousada, fora de sala de aula.

\section{REFERÊNCIAS BIBLIOGRÁFICAS}

ABREU, C. (s.d.) Meus oito anos. In BANDEIRA, M. Apresentação da Poesia Brasileira-seguida de uma Antologia de Poetas Brasileiros. Prefácio de Otto maria Carpeaux. Rio de Janeiro: Ediouro. Coleção Prestígio.

BAKHTIN, M. (2010). O problema do Conteúdo, do Material e da Forma na Criação Literária. In Questôes de Literatura e Estética (A Teoria do Romance) (1924/1974). Tradução do russo de Aurora Bernardini et al. 6a . ed. São Paulo: Hucitec Editora, p. 13-70.

BARBOSA, J. P. (2001) Trabalhando com os Gêneros do Discurso: Uma Perspectiva Enunciativa para o Ensino de Lingua Portuguesa. Tese de Doutoramento. São Paulo: LAEL / PUC-SP.

BAZERMAN, C. (2006) Gênero, Agência e Escrita. Organização: Angela Paiva Dionísio e Judith Chambliss Hoffnagel. Tradução e Adaptação: Judith Chambliss Hoffnagel. São Paulo: Cortez.

BERALDO, A. (1990) Trabalhando com poesia. São Paulo: Ática. Vol. 1.

BRITO, A. C. de. (2002) Cacaso: lelo-lero [1967-1985]. São Paulo: Cosac \& Naify; Rio de Janeiro: 7 Letras.

CARVAlHO, H. (2015) Poemas Metalinguísticos de Ferreira Gullar: Uma Proposta de Sequência Didática Interdisciplinar. In MICHELETTI, G; SPARANO, M. Estilística: Discurso, texto e ensino. São Paulo: Terracota. Ebook.

COSSOM, R. (2006) Letramento literário. São Paulo: Contexto.

FIAD, R. S. (2008) Ensino e autoria. In TFOUNI, Leda Verdiani (org.) Múltiplas faces da autoria. Ijuí: Ed. Inijuí. Coleção Linguagens.

GEBARA, A.F.L. (2010) O ensino singular dos gêneros poéticos: reflexões e propostas. Tese de Doutoramento. DLCH - FFLCH - USP. 
GOLDSTEIN, N. S.; LOUZADA, M. S. O.; IVAMOTO, R. M. F. E. (2009) Português $6^{\circ}$. a $9^{\circ}$. ano [coleção didática]. São Paulo: Pueri Domus Escolas Associadas. Vol. 4.

INSTITUTO ANTÓNIO HOUAISS; UOL. (2012) Grande Dicionário Houaiss da Língua Portuguesa Beta. Disponível em http://houaiss.uol.com.br/ Acesso em 22-12-2015.

JOLIBERT, J. (1994) Formando crianças produtoras de texto. Tradução Walkiria M.F. Settineri e Bruno C. Magne. Porto Alegre: Artes Médicas. Volume II.

JOLIBERT, J.; SRAÏKI, C. (2008) Caminhos para aprender a ler e escrever. Tradução Ângela Xavier de Brito. Revisão técnica Maria Manuela de Castro Mendes Leal Anabuki. São Paulo: Contexto.

JOLLES, A. (1976) Formas simples - legenda, saga, mito, adivinba, ditado, caso, memorável, conto, chiste. Trad. Álvaro Cabral. São Paulo: Cultrix.

LERNER, D. (2008) Ler e escrever na escola: o real, o possível e o necessário. Prefácio de Emilia Ferreiro. Tradução de Ernani Rosa. Revisão Técnica de Telma Weisz. Porto Alegre: Artmed. (reimpr.)

MAINGUENEAU, D. (2008) A propósito do ethos. Tradução de Luciana Salgado. In MOTTA, A. R., SALGADO, L. (orgs.) Ethos discursivo. São Paulo: Contexto.

MOTTA, A. R., SALGADO, L. (2006) Discurso Literário. Tradução de Adail Sobral. São Paulo: Contexto.

MARTINS, N. S. (2003) Introdução à Estilística: A Expressividade na Língua Portuguesa. 3. ed. São Paulo: T. A. Queiroz.

MATÊNCIO, M. de L. M. (2006) Letramento na formação do professor - Integração a práticas discursivas acadêmicas e construção da identidade profissional In CORREA, M. L. G.; BOCH, F. (orgs.). Ensino de lingua: representação e letramento. Campinas (SP): Mercado de Letras. (Coleção Ideias sobre linguagem).

MICHELETTI, G. (2000) Leitura e construção do real: o lugar da poesia e da ficção. São Paulo: Cortez, 2000. Coleção Aprender e Ensinar com Textos; v. 4.

NEVES, C. A. de B. (2014) A Literatura no ensino médio: os gêneros poéticos em travessia no Brasil e na França. Tese de Doutoramento. Campinas, IEL - UNICAMP.

NOGUEIRA, S. H. (2008). Da leitura poética à produção do artigo acadêmico científico. Tese de Doutoramento. São Paulo, DLCV - FFLCH - USP.

PADILHA, S. (2011) Agrupamentos de gêneros poéticos: novas possibilidades de agrupamento com base nas contribuições de M. Bakhtin. In Anais do VI Simpósio Internacional de Gêneros Textuais - SIGET, Natal. Arquivo Pdf. Disponível em http://www. cchla.ufrn.br/visiget/pgs/pt/anais/Artigos/Simone\%20de\%20Jesus\%20Padilha\%20 (MeEL-UFMT).pdf Acesso em 15-12-2015.

PAES, J. P. (2008). Poesia Completa. Apresentação de Rodrigo Naves. São Paulo: Companhia das Letras.

PESSOA, F. (1980). O Eu profundo e os outros eus: seleção poética. 9. ed. Seleção e nota editorial de Afrânio Coutinho. Rio de Janeiro: Nova Fronteira. 
SCHNEUWLY, B.; REVAZ, F. (2002) Expression écrite - lire pour ecrire, écrire pour lire: une méthode pour maitriser l'écrit. CM1. Paris: Nathan.

SCHNEUWLY, B.; REVAZ, F. (1994) Expression écrite - lire pour ecrire, écrire pour lire: une méthode pour maitriser l'écrit. CM2. Paris: Nathan.

SCHNEUWLY, B.; SANDON, J.M. (2002) Expression écrite - lire pour ecrire, écrire pour lire: une méthode pour maitriser l'écrit. CE2. Guide Pédagogique. Paris: Nathan.

TEZZA, C. (2003) Entre a prosa e a poesia: Bakbtin e os formalistas russos. Rio de Janeiro: Record.

TEZZA, C. (2006) Poesia. In BRAIT, B. (org.) Bakbtin: Outros Conceitos-chave. São Paulo: Contexto.

TRAVAGLIA, L. C. (2002) Gramática e Interação: uma proposta para o ensino de gramática no $1^{\circ}$ e $2^{\circ}$ graus. 8. ed. São Paulo: Cortez.

Recebido: 10/02/2016

Aceito: 11/03/2016 